\title{
Mediterranean diet and overall mortality differences in the European Union
}

\author{
Dimitrios Trichopoulos ${ }^{1,2, *} \dagger$ and Pagona Lagiou ${ }^{1,2}$ \\ 'Department of Hygiene and Epidemiology, School of Medicine, University of Athens, 75 M. Asias Street, \\ GR-1 15 27, Athens, Greece: ${ }^{2}$ Department of Epidemiology, Harvard School of Public Health, 677 Huntington \\ Avenue, Boston, MA 02115 , USA
}

\begin{abstract}
Objective: To assess whether the Mediterranean diet contributes to overall mortality differences and trends between Mediterranean and non-Mediterranean European Union (EU) countries.

Design: Routinely recorded adjusted overall mortality and food availability data in Mediterranean and non-Mediterranean EU countries. A Mediterranean diet score designed a priori was used as instrument.

Setting: Fifteen EU countries in the 1960s and the 1990s.

Subjects: The general population in the 15 EU countries.

Results: The difference between Mediterranean and non-Mediterranean EU countries in a 7-point Mediterranean diet score was reduced from 2.9 in the 1960 s to 1.6 in the 1990s. This reduction may underlie the reduction in the difference in general mortality between these countries, from about 100 deaths per 100000 person-years in the early 1970 s to about 50 deaths per 100000 person-years in the 1990s.

Conclusions: The decline in overall mortality in the $15 \mathrm{EU}$ countries over the last 25 years is probably unrelated to diet. However, the gradual loss of the survival advantage of Mediterranean EU citizens, compared with other EU citizens, may be linked to the gradual abandonment by the former of their dietary traditions.
\end{abstract}

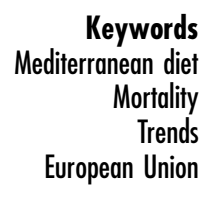

There is a vast literature concerning the role of particular macro- and micro-components of diet in the causation of coronary heart disease and various forms of cancer $^{1-4}$, diseases which together are responsible for approximately half of all deaths in the European Union (EU) ${ }^{5}$. Considerably less research has been conducted on what appears to be the main concern of the average person, that is: what dietary pattern, rather than specific dietary components, is associated with reduced mortality overall, rather than risk for specific diseases? ${ }^{6}$ There are at least two explanations for this. First, scientists tend to be analytical and, thus, focus on different diseases with distinct pathogenic processes and not on the more abstract concept of health. Second, the conceptualisation and operationalisation of dietary patterns are fraught with difficulties ${ }^{7}$.

Nevertheless, because many of the dietary components that have been reported to reduce the risk of cardiovascular diseases and many forms of cancer in the Western world are integral parts of the Mediterranean $\operatorname{diet}^{8}$, and also because Mediterranean populations seem to enjoy unexpectedly good health ${ }^{9}$, a few groups have attempted to investigate Mediterranean dietary patterns

†Recipient of the IV Grande Covian Award. in relation to mortality ${ }^{10-13}$. To overcome the need for prolonged follow-up, these groups have focused on elderly people, with the implicit assumption that age is not an important modifier of the effect of diet on mortality. Moreover, all the groups have relied on a score defined a priori, which was meant to incorporate the principal characteristics of the Mediterranean diet. The score has proved its usefulness but could be further improved; for example, by attaching weights to the individual components and by taking into account the consumption of fish (not included in the original version of the score) $)^{10}$.

We report here on attempts to evaluate patterns of overall mortality, in the early 1970s and the 1990s, in Mediterranean countries of the EU, particularly Spain, Italy and Greece, as well as in the remaining EU countries, in conjunction with the corresponding dietary intakes in the 1960s and 1990s. We contributed to an earlier study ${ }^{14}$ in which we indicated that the widespread adoption of the Mediterranean diet by northern European populations could reduce the overall incidence of cancer in these populations by up to $10 \%$. Total mortality, however, is more difficult to study than incidence of diet-related cancers, because it shows powerful secular trends and depends strongly on poorly defined exposure variables like quality and coverage of health care. 


\section{Materials and methods}

Overall mortality data, age-adjusted to the standard European population, were retrieved from the Health for All database of the World Health Organization for the early 1970 s and the $1990 s^{5}$. For Italy, Spain and Greece population-weighted averages were calculated, whereas the mortality rates for the rest of the 15-member EU were derived by subtraction. The results are shown in Table 1 .

We also retrieved food availability data recorded in the balance sheets (FBSs) of the Food and Agriculture Organization of the United Nations ${ }^{15}$. We chose the average availability of main food groups, for the periods 1961-1970 and 1990-1999, for Italy, Spain and Greece combined (population-weighted averages) and, by subtraction, the rest of the 15-member EU. The results, expressed in terms of per capita availability $\left(\mathrm{g} \mathrm{day}^{-1}\right)$, are indicated in Table 2. For added dietary lipids, we opted for the ratio of lipids of vegetable origin to those of animal origin. It should be noted that, in the FBSs, consumption of alcoholic beverages is expressed in quantities irrespective of ethanol content.

To crudely estimate the average Mediterranean diet score in the three Mediterranean countries and the rest of the EU, a cut-off value was set at the mean of the averages of the two groups of countries for each of the dietary components. We decided to combine vegetables and legumes, because of their similarity in origin and composition and the limited consumption of the latter.

Table 1 Approximate mortality rates from all causes in the Mediterranean countries and the rest of the 15-country European Union (EU), in the 1970s and 1990s, age-standardised to the European standard population

\begin{tabular}{lc}
\hline & $\begin{array}{c}\text { Mortality rate } \\
\text { (per 100 000 person-years) }\end{array}$ \\
\hline $1970 s$ & \\
Mediterranean & 960 \\
Rest of EU & 1060 \\
1990s & 680 \\
Mediterranean & 730 \\
Rest of EU & \\
\hline
\end{tabular}

We assumed that the standard deviation in each dietary component is about half the corresponding mean and we calculated the fraction of the population in the Mediterranean and the remaining EU countries that acquire the one unit reserved for each of the seven dietary components. One unit was assigned to those who consumed higher than the cut-off for vegetables (including legumes), fruits, cereals, added lipid ratio and alcoholic beverages, and lower than the cut-off for meat and dairy products.

\section{Results}

During a 25-year period, mortality from all causes declined by about $30 \%$ in the EU countries. The decline was somewhat more limited in the Mediterranean countries (280 fewer deaths per 100000 person-years, or 29\%) than in the rest of the EU (330 fewer deaths per 100000 person years, or 31\%), in both absolute and relative terms. This general decline probably reflects general socio-economic improvement, whereas diet is unlikely to have played a major role.

During the corresponding period, the diet of the nonMediterranean citizens of the EU has shown some indications of improvement, reflected in the increased consumption of fruits and vegetables, and perhaps a shift in added lipids from animal to plant origin (Table 2). The Mediterranean diet score of the nonMediterranean EU citizens increased from about 2 to about 2.5 during the study period. In contrast, the diet of the Mediterranean citizens of the EU has deteriorated, mostly because the consumption of meat has more than doubled and there has been a shift in added lipids from vegetable oils to animal fats (Table 2). The Mediterranean diet score of the Mediterranean EU citizens was reduced from 4.9 to 4.1. Therefore, the difference in the score, which was 2.9 in the 1960s, became 1.6 in the 1990s. This reduction may underlie the reduction in the difference in general mortality between non-Mediterranean and Mediterranean EU countries, from about 100 deaths per 100000 personyears in the early 1970s to about 50 deaths per 100000 person-years in the 1990s.

Table 2 Mean per capita availability (in g day ${ }^{-1}$ ) of selected food groups, and ratio of vegetable oils to animal fats, in the Mediterranean countries and the rest of the 15-country European Union (EU), in the early 1960 s and early 1990s

\begin{tabular}{|c|c|c|c|c|c|c|c|c|}
\hline & Fruits & Vegetables & Legumes & Cereals & Meat & Dairy products & $\begin{array}{c}\text { Vegetable } \\
\text { oils/animal } \\
\text { fats }\end{array}$ & $\begin{array}{c}\text { Alcoholic } \\
\text { beverages }\end{array}$ \\
\hline \multicolumn{9}{|l|}{$1960 \mathrm{~s}$} \\
\hline Mediterranean & 264 & 416 & 19 & 435 & 105 & 376 & 6.3 & 274 \\
\hline Rest of EU & 217 & 215 & 6 & 288 & 189 & 583 & 0.1 & 332 \\
\hline \multicolumn{9}{|l|}{$1990 \mathrm{~s}$} \\
\hline Mediterranean & 341 & 500 & 16 & 372 & 248 & 599 & 4.4 & 245 \\
\hline Rest of EU & 279 & 257 & 7 & 272 & 236 & 682 & 0.2 & 360 \\
\hline
\end{tabular}

Source: Food and Agriculture Organization Food Balance Sheets ${ }^{15}$. 


\section{Discussion}

The data in this study indicate that the remarkable decline in overall mortality in the 15 EU countries over the last 25 years is probably unrelated to diet and more likely reflects increased wealth, higher treatment effectiveness for some common diseases (particularly coronary heart disease), the reduction in prevalence of tobacco smoking in most EU countries and more comprehensive health coverage. In contrast, the gradual loss of the survival advantage of the Mediterranean EU citizens, compared with other EU citizens, may be linked to the gradual abandonment by the former of their dietary traditions and the adoption of healthier dietary habits by the latter.

There are several limitations in this analysis. Large sections of the populations of France and even Portugal can be thought of as Mediterranean in terms of their diet and lifestyle. We have opted for an operational definition that prioritised specificity over sensitivity. There is heterogeneity in both the mortality and the dietary data, but this is unavoidable when an attempt is made to compare large geographical areas. The FBS data refer to availability ('food disappearance data') rather than consumption and have other limitations stemming from their routine nature. However, these are the only data available for all countries for the two time periods under investigation. The scientific evidence concerning the health implications of dairy product consumption is equivocal $^{1-3}$, and it is difficult to accommodate the wellknown bimodal influence of alcohol intake on health in a score when the score is applied to a population rather than individuals (an elevated per capita consumption may reflect a welcome widespread consumption of modest quantities or an unacceptable very high consumption by a small minority). Moreover, fish intake has not been taken into account, although fish is an important dietary element of several Mediterranean populations and favourably affects cardiovascular health ${ }^{16}$. We acknowledge these problems, but we decided to adhere to the original definition of the Mediterranean diet score in order to avoid the criticism of post hoc alteration of a research instrument. Finally, our calculations for a Mediterranean diet score at a population level rely on several assumptions that may be unrealistic or impossible to validate. Nevertheless, the semi-quantification generates results compatible with the qualitative descriptive assessment.

We are not the first to point out that the diet of Mediterranean peoples is gradually moving away from its traditional and beneficial characteristics ${ }^{14,17}$. Nor are we the first to indicate that this shift is not reflected in a deterioration of health indicators, probably because of counterbalancing influences generated by prosperity and other changes in lifestyle and improvement in treatment effectiveness $^{18}$. However, our data indicate that the loss of the survival advantage of the Mediterraneans over their
non-Mediterranean EU counterparts has followed in time, and perhaps has been caused by, changes in the diet of the former.

\section{References}

1 World Cancer Research Fund (WCRF)/American Institute for Cancer Research (AICR). Food, Nutrition and the Prevention of Cancer: A Global Perspective. Washington, DC: WCRF/AICR, 1997.

2 Willett W. Nutritional Epidemiology, 2nd ed. New York: Oxford University Press, 1998; 528.

3 Willett WC, Trichopoulos D. Summary of the evidence: nutrition and cancer. Cancer Causes \& Control 1996; 7: $178-80$.

4 Tavani A, La Vecchia C. Fruit and vegetable consumption and cancer risk in a Mediterranean population. American Journal of Clinical Nutrition 1995; 61(Suppl. 6): 1374S-7S.

5 World Health Organization (WHO), Regional Office for Europe. Health for All Database. Copenhagen: WHO, 1999.

6 Willett WC. Diet and health: what should we eat? Science 1994; 264: 532-7.

7 Trichopoulos D, Lagiou P. Dietary patterns and mortality. British Journal of Nutrition 2001; 85: 133-4.

8 Willett WC, Sacks F, Trichopoulou A, Drescher G, FerroLuzzi A, Helsing E, et al. Mediterranean diet pyramid: a cultural model for healthy eating. American Journal of Clinical Nutrition 1995; 61(Suppl. 6): 1402S-6S.

9 Trichopoulos D, Lagiou P, Trichopoulou A. Evidence-based nutrition. Asia Pacific Journal of Clinical Nutrition 2000; 9(Suppl.): S4-9.

10 Trichopoulou A, Kouris-Blazos A, Wahlqvist M, Gnardellis C, Lagiou P, Polychronopoulos E, et al. Diet and overall survival in elderly people. British Medical Journal 1995; 311: 1457-60.

11 Osler M, Schroll M. Diet and mortality in a cohort of elderly people in a north European community. International Journal of Epidemiology 1997; 26: 155-9.

12 Kouris-Blazos A, Gnardellis C, Wahlqvist ML, Trichopoulos D, Lukito W, Trichopoulou A. Are the advantages of the Mediterranean diet transferable to other populations? A cohort study in Melbourne, Australia. British Journal of Nutrition 1999; 82: 57-61.

13 Lasheras C, Fernandez S, Patterson AM. Mediterranean diet and age with respect to overall survival in institutionalized, nonsmoking elderly people. American Journal of Clinical Nutrition 2000; 71: 987-92.

14 Trichopoulou A, Lagiou P, Kuper H, Trichopoulos D. Cancer and Mediterranean dietary traditions. Cancer Epidemiology, Biomarkers \& Prevention 2000; 9: 869-73.

15 Food and Agriculture Organization of the United Nations (FAO). FAO Statistical Databases. Food Balance Sheets. Rome: FAO, 2001.

16 Albert CM, Campos H, Stampfer MJ, Ridker PM, Manson JE, Willett WC, et al. Blood levels of long-chain $n-3$ fatty acids and the risk of sudden death. New England Journal of Medicine 2002; 346: 1113-8.

17 Serra-Majem L, La Vecchia C, Ribas-Barba L, Prieto-Ramos F, Lucchini F, Ramon JM, et al. Changes in diet and mortality from selected cancers in southern Mediterranean countries, 1960-1989. European Journal of Clinical Nutrition 1993; 47(Suppl. 1): S25-34.

18 Serra-Majem L, Ribas L, Tresserras R, Ngo J, Salleras L. How could changes in diet explain changes in coronary heart disease mortality in Spain? The Spanish paradox. American Journal of Clinical Nutrition 1995; 61(Suppl. 6): 1351S-9S. 